\title{
CLINICAL AND RADIOGRAPHIC EVALUATION OF ALOE VERA GEL IN TREATMENT OF BADLY DECAYED PRIMARY ANTERIOR TEETH
}

\author{
Abd-Elhamid A*, Barakat I**, AL-Bayoumy $\mathrm{S}^{* *}$
}

\begin{abstract}
The aim: to study the clinical and radiographic evaluation of Aloe Vera gel in the treatment of badly decayed primary anterior teeth. Methodology: Forty teeth have early childhood caries were selected from pedodontic Outpatients Clinic, Faculty of Dental Medicine, Boys,Cairo, Al-Azhar University, during period of 2014-2016. The teeth were classified into two equal groups (A\&B) each group formed of 20 teeth. Group (A) was received mixture of Aloe Vera gel with zinc oxide powder during pulpectomy procedure, while group (B) was received zinc oxide eugenol past during pulpectomy procedure. Results: clinical and radiographic examination revealed in group (A), the success rate of Aloe Vera mix was (95\%), after 6 successive months with no statistical significance difference $(\mathrm{P}=0.00)$. In group (B) success rate of zinc oxide eugenol past was $(90 \%)$ after 6 successive months with no statistical significance difference $(\mathrm{P}=0.00)$.
\end{abstract}

Conclusion : A loe Vera mix proved better clinical and radiographic results than zinc oxide eugenol .

\section{INTRODUCTION}

Caries in very young children known as Early Childhood Caries (ECC) may be defined according to the American Academy of Pediatric Dentistry "as the presence of one or more decayed, missing (due to caries), or filled tooth surfaces in any primary tooth in a child 71 month of age or younger".

Early loss of the primary anterior teeth may bring about functional problems in mastication and phonetics, lead to the development of Parafunctional habits such as tongue thrust, and impair the aesthetic appearance.

The use of zinc oxide and eugenol (ZOE) to fill root canals of primary teeth was described by Sweet in 1930. Since the $1930 \mathrm{~s}^{(1)}$. Other authors have advocated the use of $\mathrm{ZOE}$ to fill the canals of primary teeth needing root canal therapyIn 1967 , it was shown that ZOE set in a dense mass resisted resorption and was very irritating to the periapical tissues in rats. In 1979, it was speculated that the resorption rate of $\mathrm{ZOE}$ and the root differed, resulting in small areas of ZOE paste possibly being retained $^{(2)}$.

Those authors felt ZOE resisted resorption and might deflect the path of eruption of the succedaneous tooth. To date, the long-term follow up PE study. Some studies have not investigated whether primary tooth PEs alter the path of the permanent tooth's eruption ${ }^{(3,4)}$. ZOE has been widely used in the primary dentition ${ }^{(5)}$. Nevertheless, some untoward reactions elicited by these materials have

\footnotetext{
* Assistant Lecturer of Pediatric Pentistry and Oral Health Department, Faculty of Dental Medicine, Boys, Cairo, AL-Azhar University .

** Lecturer of Pediatric Dentistry and Oral Health Department, Faculty of Dental Medicine, Boys, Cairo, AL-Azhar University

*** Professor and head Pediatric Dentistry and Oral Health Department, Faculty of Dental Medicine, Boys, Cairo, AL-Azhar University
} 
limited their use. These adverse effects include being irritating for the tissues and triggering foreign-body reactions within the periapical tissues, particularly when extruded into the extra dental space. The irritating potential of the zinc oxide and eugenolbased materials is currently attributed to the eugenol. Another shortcoming that has restricted the use of these compounds is their low resorption capacity, due to which zinc oxide and eugenol particles are left within the periapical tissues as the physiological root resorption occurs ${ }^{(6)}$.

Aloe Vera derives its name from the Arabic word "alloeh" and from Latin word "Vera" meaning shinning bitter substance and true respectively ${ }^{(7)}$.

Antibacterial, antifungal, antiviral effects: Streptococcus pyogenes and streptococcus faecalis are two microorganisms which have been inhibited by the Aloe Vera $\mathrm{ge}^{\mathrm{l}(8)}$. It was found that aloe Vera gel shows bactericidal activity against both cariogenic and periodontopathic bacteria ${ }^{(9)}$. It is a chronic inflammatory disorder affects the skin and oral mucosa. Since it is chronic in nature no defin- 3 -ite cure has been discovered. Topical application of aloe Vera 3 times a day provides the pain relief, improves the oral lesion and quality of the patient (10). Steroids are the most recommended treatment in the case of lichen planus however prolong use of steroids is associated with multiple systemic complications which provide aloe Vera an added advantage due to its minimal side effects also when compared with triameinolide better results were obtained with topical aloe Vera ${ }^{(11)}$.

Pulpotomy refers to removal of coronal pulp once removing the coronal pulp with a spoon excavator and then irrigate with saline and finally when hemorrhage is controlled with wet cotton pellets. Aloe Vera gel is applied to the remaining pulp stumps followed by non eugenol cements and permanent restoration was found to be effective and patient is also free from symptoms and prevent reinfection. There was no evidence of abscess, mobility, pain or swelling was found. Patient was follow up after 30 days and 60 days to check vitality of teeth ${ }^{(12)}$.

A study was done to evaluate the antimicrobial effectiveness of root canal filling materials.6 root canal filling materials aloe Vera, sterile water with zinc oxide and eugenol, zinc oxide, eugenol with aloe Vera, calcium hydroxide and sterile water and calcium hydroxide, aloe Vera and idoform (metapex) and vaselin (control) were used. Aloe Vera with sterile water found to have maximum antimicrobial activity ${ }^{(13)}$.

Aloe Vera has shown antimicrobial effect against resistant microorganism found in the root canal. In many cases the causes for the failure of endodontic treatment is due to persistent or secondary intraradicular infection ${ }^{(14)}$. It has been found enterococcus faecalis has been associated with failure of root canal therapy.

Suresh Chandra conducted a study on in vitro antibacterial efficacy of aloe Vera extract on resistant antimicrobial strains in endodontic. The antimicrobial effect of alcohol, chloroform exacts of aloe Vera gel was investigated on different strains of bacteria and yeasts. This study has concluded aloe Vera show significant zone of inhibition against E. faecalis ${ }^{(15)}$.

\section{SUBJECTS, MATERIALS AND METHODS}

1. Study design: This study was interventional and observational study.

2. Study setting and sample size: This study was carried out in period between November 2014 and November 2016, on 80 badly decayed primary anterior teeth that indicated for pulpectomy. These teeth were selected from child patient of Pedodontic Dentistry Outpatients Clinic, Faculty of Dental Medicine, Boys, Cairo, Al-Azhar University. The procedure was discussed in briefly for each patient s parent and informed consent was taken from each one. 


\section{A-Inclusion criteria:}

1. Patient and parent cooperation.

2. Absence of any systemic disease which would contraindicate pulp therapy.

3. No previous history of antibiotic therapy for at least 2 weeks.

4. Presence of clinical signs or symptoms suggesting a vital or non- vital tooth.

5. Possibility for establishing a final restoration of the tooth.

\section{Primary anterior teeth also met the following ra- diographic criteria:}

1. Presence or absence of periapical radiolucency.

2. Presence of healthy layer overlying bone between permanent tooth bud and deciduous teeth.

3. Absence of advanced physiologic or pathologic root resorption (no more than $1 / 3$

3- Sample size: A total of 80 teeth were classified into two equal groups.

Group A: 20 badly decayed primary anterior teeth received Aloe Vera mix.

Group B: 20 badly decayed primary anterior teeth received zinc oxide eugenol paste.

\section{5- Observation:}

The tooth was observed clinically and radiographically through the period of this study.

\section{Statistical Analysis}

The significant differences between groups was assessed using $t$-test and one-way analysis of variance (ANOVA). Values of $p \leq 0.05$ were considered significant. These analyses were done using SPSS 18.0 statistical software.

\section{RESULTS}

Group (A): This group composed of twenty teeth which received mixture of zinc oxide powder with aloe Vera gel in badly decayed primary anterior teeth during pulpectomy procedure.

\section{Success rate of the group A:}

Only 19 teeth (95\%) of this group responded positively to mixture of zinc oxide with aloe Vera gel in pulpectomy procedure and appear normal as evaluated and measured by clinical and radiographic assessments for six successive months. while the other one teeth $(5 \%)$ was respond negatively and were retreated or extracted. Radiographically, the succeeded teeth showed normal root and periapical area after pulpectomy by mix of zinc oxide with aloe Vera gel (Fig.1).

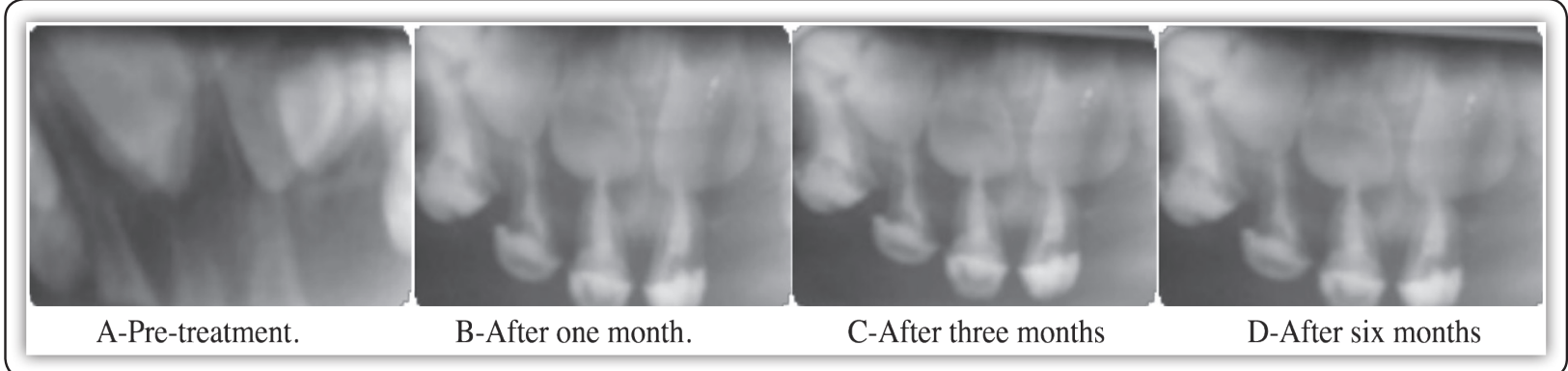

FIG (1) X-Rays of pulpectomy by mix of Zinc oxide with aloe Vera gel (group A). 
Group (B): this group composed of twenty teeth which receive zinc oxide eugenol paste in badly decayed primary anterior teeth during pulpectomy procedure.

Success rate of the group (B): Only 18 teeth $(90 \%)$ of this group responded positively to ZOE paste in pulpectomy procedure and appear normal as evaluated and measured by clinical and radiographic assessments for six successive months (Fig. 2), while the other 2 teeth (10\%) was respond negatively and were retreated or extracted.

Radiographically, the succeeded teeth showed normal root and periapical area after pulpectomy by zinc oxide eugenol.

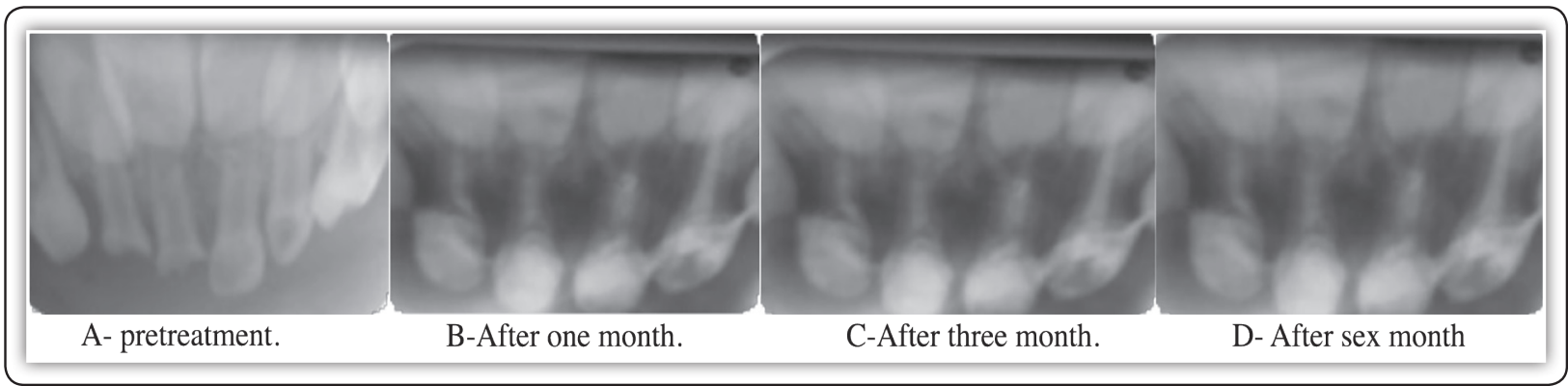

Fig (2) X-Rays of pulpectomy by zinc oxide eugenol (group B).

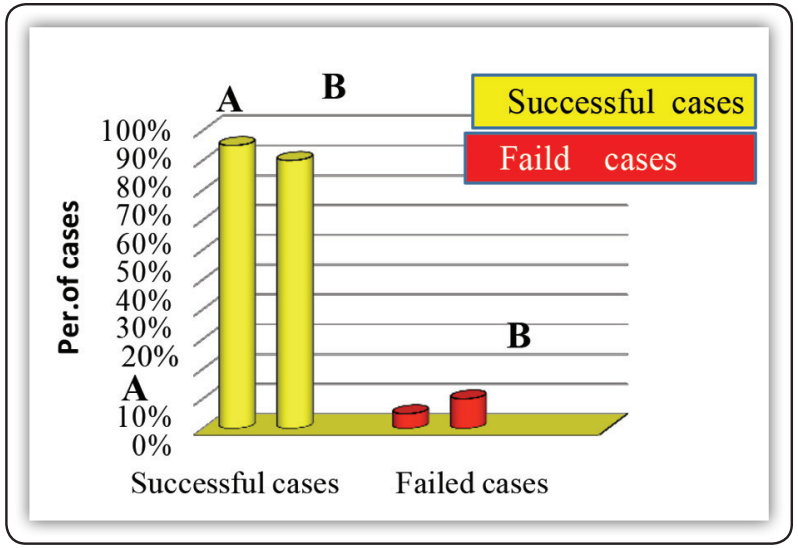

FIG (3) Comparison between mixture of zinc oxide with aloe Vera gel group(A) and ZOE group (B) regarding the success rate.

\section{DISCUSSION}

Early childhood caries (ECC) is a serious public health problem in both developing and industrialized countries, ECC has been characterized by first affecting the primary anterior maxillary teeth, followed by involvement of the primary molars ${ }^{(16)}$.
The results of the present study showed that two visit pulpectomy with $\mathrm{ZOE}$ as root canal filling material was successful in $90 \%$ of the teeth treated as verified by clinical and radiographic examinations. Successful pulpectomies was clinically asymptomatic and radiographically reduced or not changed the radiolucency before the treatment. This result was agreement with other studies $^{(17-22)}$.

According to other investigator ${ }^{(17)}$, the success rate was $100 \%$ for ZOE pulpectomies in a follow up period of 18 months. Other investigators reported that the success rate of ZOE paste is $86.1 \%$ after at least a 5-year follow up of 41 pulpectomized teeth $^{(18)}$. Reddy et al(2003) ${ }^{(19)}$ reported a success rate of ZOE paste was $80 \%$ in a follow up of 9 months.

According to two other studies, the success rate of ZOE was $83.3 \%$ and $88.6 \%$ in follow up periods of 6 and 9 months respectively ${ }^{(20,21)}$ and in a systematic review the overall success rate of $\mathrm{ZOE}$ was between $85-100 \%^{(22)}$. 
The low percentage of failure rate of ZOE paste as obturating material in badly decayed primary anterior teeth during pulpectomy procedure was $10 \%$, due to drawbacks of ZOE such as slow rate of resorption, irritation to the periapical tissues, necrosis of bone and cementum, and alters the path of eruption of succedaneous tooth ${ }^{(23)}$.

To improve the properties and success rate, $\mathrm{ZOE}$ has been tried with many compounds, but the addition of these compounds neither increased the success rate nor made the material more resorbable as compared to ZOE alone. Eugenol also acts as an irritable factor in the periapical region and when it is mixed zinc oxide powder, it sets as a hard mass. Whereas zinc oxide powder, if mixed with aloe vera gel, provides the following advantages: it does not set, its ease of placement, easily retrievable nature. So, in this study, we have used zinc oxide powder with aloe Vera gel to check the efficacy of this combination as an obturating material for primary teeth.

Aloe Vera is an herbal and naturally found material. Herbal compounds are being used by about $80 \%$ of the world population primarily in the developing countries for primary health care.

The present study showed that the success rate of mixture of zinc oxide powder with aloe Vera gel as obturating material during pulpectomy procedure is $95 \%$. This result is agreement with another study ${ }^{(24)}$. The high success rate of mixture of zinc oxide powder with aloe Vera gel may be due to the beneficial effects of Aloe Vera which can be used for various therapeutic antifungal, antiviral, moisturizing, and pain-relieving properties, the antimicrobial effects of aloe vera have been attributed to the plant's natural anthraquinones: aloe emodin, aloetic acid, aloin, anthracene, anthranol, barbaloin, chrysophanic acid, ethereal oil, ester of cinnamonic acid, isobarbaloin, and resistannol ${ }^{(25)}$.

\section{REFERENCE}

1. Sweet C. Procedure for treatment of exposed and pulpless deciduous teeth. J Amer Den Assn 1930;17: 1150-53.

2. Kopel H. Root canal therapy for primary teeth. J Mich Dent Assoc 1970; 52:28-33

3. Ranly D, Garcia-Godoy F. Reviewing pulp treatment for primary teeth. J Am Dent Assoc 1991; 122:83-85.

4. Love R. Endodontic treatment in primary dentition. Aust Endod J 2004; 30:59-68

5. 5- Yacobi R, Kenny D, Judd P, Johnston D. Evolving primary pulp therapy techniques. J Am Dent Assoc 1991; 122: 83-85.

6. Primosch R, Ahmadi A, Setzer B, Guelmann M. A retrospective assessment of zinc oxide eugenol pulpectomies in vital maxillary primary incisor successfully restored with composite resin crowns. Pediatr Dent 2005; 27:470-77.

7. Sardana, k, Indusekar T, Bhavana G, saraj and neha sheoran. Current perspectives on the use of aloe Vera in dentistry". Erika Tayal; Pedod Prev J 2010; 5: 23-26.

8. Heggers JP,kucukcelibi A, stabenou CJ xo F, Broemeling $\mathrm{LD}$, robson MC, winters WD. Wound healing effects of the aloe gel and other topical antibacterial agents in rat skin. Phytotherapy 1995; 9: 455-57.

9. Radwan-oczko M. topical application of drugs used in treatment of oral lichen planus lesions. Adv Clin Exp Med 2013;22:893-98.

10. Reddy RL, reddy RS, Ramesh T, singh TR, swapna LA, laxmi NV. Randomized trial of alovera gel vs triamcinolone automide ointment in the treatment of oral lichen planus. Quintessence int.2012;43:793-800.

11. Sudarshan $R$, annigeri $G$, sree vijayabala $G$. aloe vera in dentistry. Indian J Stomatol 2013;4:45-47.

12. Pradeep AR, agarwal E, Naik SB. Clinical and microbiologic effects of commercially available dentrifice containing aloe vera a randomized controlled clinical trial. J Periodontol 2012; 83:797-804

13. J.F siquira JR. aetiology of root canal treatment failure: why well treated teeth can fail. Int Endod J 2001; 34: 10.

14. Caufield PW, Cutter GR, Dasanayake AP. Initial Acquisition of Mutans Streptococci by Infants: Evidence for a Discrete Window of Infectivity. J Dent Res. 1993; 72:37-45.

15. Pareek S, nagaraj A, Sharma P,atri M et al. disinfection of dental unit water line using aloe vera: in vitro study. Int $\mathrm{J}$ Dent 2013 ; 110- 16. 
16. Motisuki C, Santos-Pinto L, Giro EM. Restoration of severely decayed primary incisors using indirect composite resin restoration technique. IN J Pediatr Dent 2005; 15:282-86.

17. Aminabadi NA, Farahani RM. The efficacy of a modified omega wire extension for the treatment of severely damaged primary anterior teeth. J Clin Pediatr Dent. 2009; 33:283-88.

18. Livny A, Assali R, Sgan-Cohen H. Early Childhood Caries among a Bedouin community residing in the eastern outskirts of Jerusalem. BMC Public Health. 2007;7:167.

19. Seminario L, Romana I. Early childhood caries: Review article. Acta Medica 2003;46 : 91-94.

20. Ozalp N, Saroğlu, I, Sönmez H. Evaluation of various root canal filling materials in primary molar pulpecto-mies: an in vivo study. Am J Dent 2005; 18:347- 50.

21. Coll J, Josell S, Casper J. Evaluation of a one-appointment formocresol pulpectomy technique for primary molars. Pediatr Dent 1985; 7:123-29.

22. Reddy VV, Fernandes. Clinical and radiological evaluation of zinc oxide-eugenol and Maisto's paste as obturating materials in infected primary teeth nine months study. J Indian Soc Pedod Prev Dent 1996; 14:39-44.

23. Barcelos R, Santos MPA, Primo LG, Luiz RR, LC Maia LC. ZOE paste pulpectomies outcome in primary teeth: a systematic review. J Clin Pediatr Dent 2015; 4: 89-94.

24. Berson R, Good D. Pulpotomy and Pulpectomy for Primary Teeth. In: Pediatric Dentistry. Stewart RE, Barber TK,Troutman KC, Wei SHY, Eds. St Louis: CV Mosby Co, 1981; 917-26.

25. Ramar K, Mungara J. Clinical and radiographic evaluation of pulpectomies using three root canal filling materials: An in-vivo study. J Indian Soc of Pedod Prev Dent 2010; 28:25-29. 